\title{
Epidemiology of Trauma Patients from the Mosul Offensive, 2016-2017: Results from a Dedicated Trauma Center in Erbil, Iraqi Kurdistan
}

\author{
Maximilian P. Nerlander ${ }^{1} \cdot$ Rawand Musheer Haweizy $^{2} \cdot$ Moayad Abdullah Wahab $^{3}$ • \\ Andreas Älgå ${ }^{1}\left(\mathbb{D} \cdot\right.$ Johan von Schreeb $^{1}$
}

Published online: 24 October 2018

(C) The Author(s) 2018

\begin{abstract}
Introduction Most epidemiological studies from conflicts are restricted to either combatants or civilians. It is largely unknown how the epidemiology differs between the two groups. In 2016, an Iraqi-led coalition began retaking Mosul from the terrorist group Islamic State of Iraq and Syria. One key institution that received trauma patients from Mosul was Emergency Management Center (EMC) in Erbil, $90 \mathrm{~km}$ away. The aim of this study was to describe the epidemiology, morbidity, and mortality of civilians and combatants admitted during the ongoing conflict.

Method This retrospective cohort study utilized routinely collected data on patients with conflict-related injuries who were admitted to EMC between October 16, 2016, and July 10, 2017. Data processing and analysis was carried out using JMP 13. Categorical variables were compared using Fisher's exact test.

Results The analysis included 1725 patients, out of which $46 \%$ were civilian. Ordnance accounted for most injuries (68\%), followed by firearms (18\%) and improvised explosive devices (IEDs) (14\%). The proportion of IED-related injuries among combatants were almost three times that of civilians. The proportions of abdominal injuries, need for surgery, laparotomies, and amputations were significantly higher among civilians than among combatants. The mortality rate was $0.5 \%$.

Discussion The fact that civilians had greater surgical needs than combatants may be explained by several factors including a lack of ballistic protection. The extremely low mortality rate indicates significant gaps in prehospital care and transport. Our results may provide useful information to guide medical preparedness and response during future conflicts.

Clinicaltrials.gov ID NCT03358758.
\end{abstract}

Maximilian P. Nerlander

maximilian.nerlander@ki.se

Rawand Musheer Haweizy

rawand_haweizy@yahoo.com

Moayad Abdullah Wahab

moabva@yahoo.com

Andreas Älgå

andreas.alga@ki.se
Johan von Schreeb

johan.von.schreeb@ki.se

1 Centre for Research on Health Care in Disasters, Department of Public Health Sciences, Karolinska Institutet, 17176 Stockholm, Sweden

2 College of Medicine, Hawler Medical University, Erbil, Iraq

3 Kurdistan Board of Medical Specialties, Erbil, Iraq 


\section{Introduction}

Between October 16, 2016, and July 10, 2017, an internationally supported coalition involving the Iraqi Security Forces (ISF), Kurdish Peshmerga, and Shia militias reclaimed the city of Mosul from the terrorist organization Islamic State of Iraq and Syria (ISIS). Estimates of total fatalities during the offensive vary. A report by the UN Assistance Mission for Iraq and the Office of the UN High Commissioner for Human Rights estimates that 2521 civilians were killed, while aggregate data compiled by the Associated Press estimate that there were between 9000 and 11,000 civilian fatalities [1,2].

The total number of patients who were in need of surgery remains unknown, but a lack of advanced trauma care close to the conflict was a significant problem, especially during the first months of fighting. During this time, injured patients had to be transported to Erbil for surgical trauma care, $90 \mathrm{~km}$ away. It took several months until a functional trauma care system, provided by national and international agencies, was in place. The system included prehospital trauma stabilization points (TSP), emergency surgical trauma care, ambulance referrals, and referral surgical trauma care. A report by the Johns Hopkins Bloomberg School of Public Health (BSPH) estimates that between 1500 and 1800 lives were saved thanks to these efforts [2].

Several studies conducted in the Eastern Mediterranean region have investigated the epidemiology of conflict-related trauma. A recent study from the Syrian conflict using mortality data from the Syrian Violation Documentation Center found that the mechanism of fatal injury to civilians varied with the stage of the conflict [3]. US military studies indicated that explosions were a leading cause of battlefield trauma in combatants [4-6]. However, to date, there are few published articles that directly compare the epidemiology of conflict-related trauma in civilians with that of combatants. When conducted, these tend to focus on a particular injury mechanism or on a specific anatomical injury site [7-10].

Injury mechanism, severity of injury, and in-hospital mortality all have implications for clinical management and resource allocation. Therefore, an expanded understanding of how the epidemiology of conflict-related trauma differs between civilians and combatants may be of value to those involved in providing surgical trauma care to any patients during modern conflicts.

This study aims to describe and compare the epidemiology, morbidity, and mortality of civilian and combatant casualties admitted to a specialized trauma care facility during the Mosul offensive.
Methods

Emergency Management Center (EMC), located approximately $90 \mathrm{~km}$ east of Mosul in Erbil, Iraqi Kurdistan, is a dedicated trauma center and one of the key medical institutions that received trauma patients from the Mosul offensive. This facility is a 108-bed referral hospital with diagnostic capabilities including computed tomography scanners, which provides general, orthopedic, and vascular surgery. EMC systematically collected data on admitted patients. A paper-based file followed the patient throughout the hospital stay. Upon discharge or death, the file was brought to a central archive. Data were manually extracted from existing files and registries to produce a line list in Microsoft Excel which was subsequently cleaned and analyzed using JMP 13. Variables included demographics, date of admission, date of discharge, injury mechanism, anatomical injury site, status as civilian or combatant, operative interventions, and length of intensive care unit (ICU) stay. Results were stratified according to standard age categories and combatant status. Categorical variables were compared using Fisher's exact test, where a $p$ value of $<0.05$ was considered significant.

The inclusion criteria for this study were any trauma patient admitted to EMC between October 16, 2016, and July 10, 2017, with an injury that was sustained in Mosul and attributable to the conflict. Two categories of patient identity were used. A combatant was defined as a person belonging to either the ISF or the Peshmerga, the main military force of Iraqi Kurdistan. A civilian was defined as a person reportedly not belonging to a warring faction and not actively participating in combat. Identity was assigned by the emergency room nurse based on the presence or absence of a uniform, the presence of a combat casualty card, and self-report. Three injury mechanisms were identified. A firearm was any weapon firing nonexplosive kinetic projectiles. Ordnance included any conventional explosives, including grenades, mortars, and rocket-propelled grenades. Improvised explosive devices (IEDs) were a heterogeneous family of explosives consisting of weaponized explosive materials. Together, ordnance and IEDs are referred to as explosives. Injury mechanism was assigned based on injuries identified by the physician and information from the ambulance services, self-report, or witnesses to the incident. In terms of outcome, a fatality was defined as a patient dying after having arrived at the hospital. Injury severity was estimated using proxy markers, including need for surgery, type of surgery, and duration of ICU admission.

Ethical permission was obtained from the Research Ethics Committee, Kurdistan Regional Government (Id: 632017). 
Table 1 Demographics, morbidity, mortality, and surgeries of patients presenting to EMC between October 16, 2016, and July 10, 2017, by any route of admission, with injuries sustained in Mosul, where the injury is attributable to the conflict and of a violent nature $(n=1725)$

\begin{tabular}{lr}
\hline & $n(\%)$ \\
\hline Mex & $1507(87)$ \\
Female & $218(13)$ \\
Identity & \\
Combatant & $932(54)$ \\
Civilian & $793(46)$ \\
Injury mechanism & \\
Ordnance & $1176(68)$ \\
Firearm & $306(18)$ \\
IED & $243(14)$ \\
Anatomical injury site & \\
Extremities & $1091(58)$ \\
Trunk & $418(22)$ \\
Head/neck & \\
In-hospital deaths & $360(19)$ \\
Surgeries & $8(0.5)$ \\
\hline Total & $n$ \\
Debridement & 1031 \\
Laparotomy & 315 \\
Amputation & 71 \\
Thoracotomy & 28 \\
\hline Inclues facial and eye & 1 \\
\hline
\end{tabular}

${ }^{a}$ Includes facial and eye injuries. Multiple injuries to different structures counted separately

\section{Results}

Data were collected on a total of 1832 consecutive patients meeting the inclusion criteria. Out of these, 107 patients were excluded due to their identity being neither combatant nor civilian. Examples include police officers and private security personnel. Thus, a total of 1725 patients were included in the final analysis.

The majority $(87 \%)$ of patients were male. Most patients were identified as combatant (54\%), followed by civilian (46\%). Most patients had been injured by ordnance $(68 \%)$ followed by firearms (18\%) and IEDs (14\%). The overall in-hospital mortality rate was $0.5 \%$ (Table 1 ).

In all standard age categories except $70+$, the majority of patients were male, even with combatants excluded. There were no female combatants represented in this dataset. The three most common age categories were 20-24, 25-29, and 30-34, and males in these categories constituted more than half of total patients (Fig. 1).

The proportion of firearm-related injuries were similar between civilians and combatants. Civilians were more likely to have been injured by ordnance, while combatants were almost three times more likely to have been injured by IEDs. Civilians were more than twice as likely to have abdominal injuries as compared to combatants. The proportion of patients undergoing surgery among civilians was more than five times that of combatants. Civilians were more than six times as likely to undergo amputation and eight times more likely to undergo a laparotomy. Among patients who required ICU care, $21 \%$ of civilians required 10 days or more in ICU, while only one combatant was in the ICU this long (Table 2).

\section{Discussion}

Males aged 20-39 years constituted more than half of the patients, and the majority of these patients were combatants. Similar observations have been made elsewhere in Iraq. Analysis of data from the Iraqi National Injury Surveillance System revealed that men in the very same age span constituted a majority of all fatal injuries from firearms [11]. The results must also be understood in the context of what is known about the wider trauma care response to the Mosul operation. The BSPH report estimates that out of 19,784 patients presenting to a total of 10 facilities during the Mosul operation, a slight majority (55\%) of patients were female [2]. Since the BSPH report includes facilities close to the battlefield, this may indicate that more males than females were referred to higher-level institutions, as males predominated in our study population.

Explosives were the leading injury mechanism among civilians and combatants alike. Studies conducted in conflicts elsewhere in the Middle East have made similar observations. A recent retrospective study of US military casualties in Iraq found that more than three quarters of casualties were due to explosives [4]. Similarly, a report by the U.S. Department of Veteran Affairs determined that $74 \%$ of casualties in the U.S. Joint Theatre Trauma Registry were due to explosives [6]. Data from Syria describing the cause of fatalities among civilians indicate that in the early stages of the conflict, firearm-related injuries were responsible for the majority of civilian fatalities, while a greater proportion of civilians were killed by explosives at later stages [3].

Civilians were more than twice as likely to sustain abdominal injuries as compared to combatants and significantly more likely to undergo laparotomies and amputations. This may have been attributable to the ballistic protection worn by combatants, which usually protects the torso through anterior and posterior steel or ceramic armor plate inserts, as well as access to armored vehicles which provide additional protection. The effect of the discrepancy in access to protection was twofold. First, civilians were at 


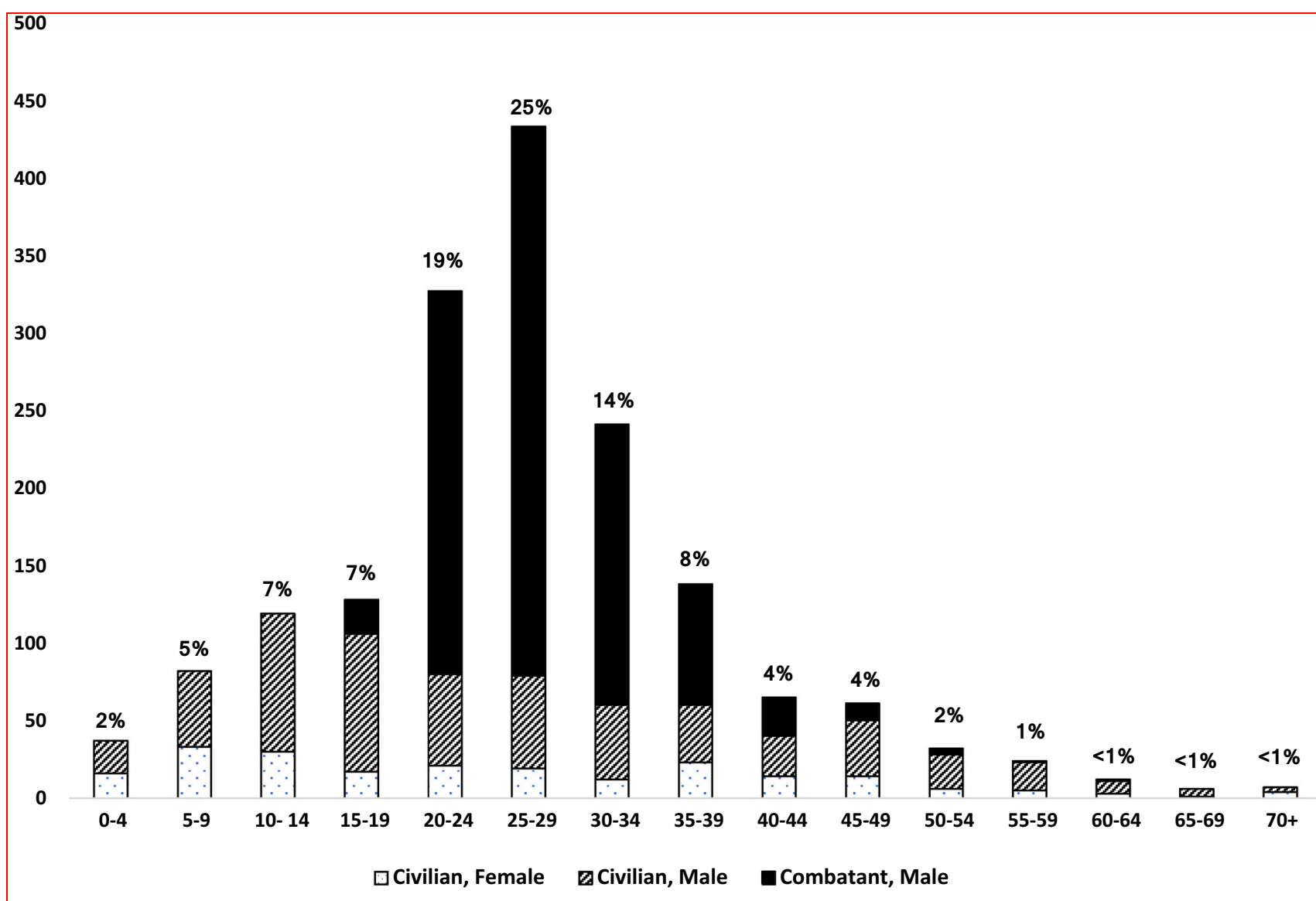

Fig. 1 Age distribution and combatant status $(n=1725)$. A total of 13 individuals whose age was unknown were excluded from the age analysis but included in the analysis pertaining to sex and combatant status

greater risk of injuries to the abdomen. Second, when injuries did occur, they were more likely to be severe due to the absence of protection, increasing the likelihood of a laparotomy being required.

Civilians were more than five times more likely to require any surgery overall and were also more likely to require lengthy ICU care. This may be reflective of ISF evacuation policies, where wounded ISF service members were evacuated to EMC, stabilized, and transported to Baghdad within $24 \mathrm{~h}$. Thus, nonurgent surgeries in this patient group were not conducted at EMC, and length of ICU care was limited.

The in-hospital mortality rate was lower than what has generally been observed in other settings. By comparison, studies from urban hospitals in India, a setting with comparable healthcare resources to Iraqi Kurdistan but with different types of injuries, reveal significantly higher inhospital trauma fatality rates. A retrospective study of trauma patients in Mumbai revealed a fatality rate of $8.1 \%$ during the first hours following admission [12]. Further, a study of 11,671 trauma admissions in five urban Indian hospitals revealed an overall 30-day mortality of $21.6 \%$, while a separate study of 11,202 trauma admissions found an in-hospital mortality of $21.4 \%[1,13]$. In the UK, a mortality study of 66,734 trauma patients involved in mass casualty events revealed an overall ER mortality of $6.5-7.6 \%$ [14]. Our results therefore suggest that the most critically injured patients died before reaching the hospital due to long transport times and significant shortcomings in prehospital care. During the Mosul operation, patients were transported in Iraqi ambulances, driven to the KurdishIraqi border where a security check was conducted, then transferred to Kurdish ambulances, and driven to Erbil. This coupled with limited healthcare provision close to the battlefield, especially during the early stages of the campaign, implies that many patients may have died prior to reaching EMC. This is supported by studies investigating the epidemiology of trauma patients in Kunduz, Afghanistan, a conflict setting with significant shortcomings in prehospital care, which found in-hospital mortality rates between 0.1 and $12.6 \%[15,16]$. The very low incidence of thoracic injuries and thoracotomies in this study is also an indication of a high prehospital mortality, since traumatic intrathoracic events such as tension pneumothoraces and 
Table 2 Injury mechanism, location of injury, surgery, and ICU care by status, $\%$ of combatants and civilians $(n=1725)$

\begin{tabular}{lccr}
\hline & Combatant, $n(\%)$ & Civilian, $n(\%)$ & $p$ value \\
\hline Injury mechanism & & & \\
Firearm & $178(19)$ & $128(16)$ & 0.11 \\
Ordnance & $570(61)$ & $606(76)$ & $<0.05$ \\
IED & $184(20)$ & $59(7)$ & $<0.05$ \\
Anatomical injury site $^{\mathrm{a}}$ & & \\
Head/neck & $193(21)$ & $156(20)$ & 0.63 \\
Upper limb & $237(25)$ & $167(21)$ & $<0.05$ \\
Lower limb & $328(35)$ & $359(45)$ & $<0.05$ \\
Abdomen & $64(7)$ & $127(16)$ & $<0.05$ \\
Thorax & $48(5)$ & $57(7)$ & 0.09 \\
Back & $65(7)$ & $57(7)$ & 0.93 \\
Required surgery & $95(10)$ & $418(53)$ & $<0.05$ \\
Type of surgery & & & \\
Laparotomy & $11(1)$ & $60(8)$ & $<0.05$ \\
Amputation & $4(0.4)$ & $24(3)$ & $<0.05$ \\
Length of ICU care & & & $<0.05$ \\
$\geq 10$ days & $1(3)$ & $14(21)$ & \\
\hline
\end{tabular}

${ }^{\mathrm{a}}$ Denominator includes 59 patients where anatomical injury site was unknown

${ }^{\mathrm{b}}$ Includes facial and eye injuries. For comparative analysis, multiple injuries to different structures are counted as one injury

${ }^{\mathrm{c}}$ Among patients requiring surgery

${ }^{\mathrm{d}}$ Among patients requiring ICU care $(n=105)$

hemothoraces can rapidly be fatal unless care is initiated early [17].

\section{Limitations}

This study was subject to a number of limitations. First, it was an analysis of data from a single center and therefore not representative of all trauma patients during the Mosul operation. Unpublished data from West Emergency Hospital, another hospital in Erbil, suggest that this facility cared for additional 2608 patients. Second, since the conflict involved irregular forces with no consistent uniform use, distinguishing combatants from civilians may have been challenging, particularly in unconscious patients who were unable to self-report. Third, due to the database in this analysis having been compiled from handwritten records, collection was subject to transcription error. Fourth, the data were subject to survival bias since, due to long transportation times and gaps in prehospital care, only patients well enough to reach care were included. As a result, critical injuries were underrepresented, which limits the generalizability for settings closer to the battlefield. Lastly, patient demographics may have been unreliable, since some patients come from socioeconomic settings where the date of birth may not have been recorded. However, due to the random nature of these uncertainties, any effect on the analysis is likely to have been limited.

\section{Conclusion}

This study was based on data collected from a dedicated trauma center providing a leading role in meeting healthcare needs during the offensive against ISIS in Mosul and as such represents the first investigation of its kind from this particular conflict. We have demonstrated that in the context of the Mosul operation, civilians and combatants that were referred to EMC had suffered different types of injuries and that civilians may have been more likely to have suffered severe injuries. The low in-hospital mortality indicates that there may be gaps in prehospital care and transportation. Additional studies conducted closer to the battlefield are needed in order to better understand what factors determine the epidemiology of conflict-related trauma patients in the early phase following injury and to what extent the availability of early resuscitation of trauma patients affects mortality.

Acknowledgements This study was funded by the Swedish National Board of Health and Welfare (Socialstyrelsen).

Author contributions MPN, HR, AÄ, and JVS designed the study. RH and WM collected the data. MPN validated and analyzed the data. MPN, HR, WM, AÄ, and JVS interpreted the data. MPN prepared the manuscript. MPN, HR, WM, Ä̈, and JVS critically reviewed the manuscript for style and content.

\section{Compliance with ethical standards}

Conflict of interest All authors declare that they have no conflict of interest.

Open Access This article is distributed under the terms of the Creative Commons Attribution 4.0 International License (http://crea tivecommons.org/licenses/by/4.0/), which permits unrestricted use, distribution, and reproduction in any medium, provided you give appropriate credit to the original author(s) and the source, provide a link to the Creative Commons license, and indicate if changes were made.

\section{References}

1. Roy N, Gerdin M, Ghosh S, Gupta A, Kumar V, Khajanchi M et al (2016) 30-Day in-hospital trauma mortality in four urban university hospitals using an indian trauma registry. World J Surg 40(6):1299-1307. https://doi.org/10.1007/s00268-016-3452-y

2. Spiegel PB (2018) The mosul trauma response. Stanford University, Palo Alto

3. Guha-Sapir D, Schlüter B, Rodriguez-Llanes JM, Lillywhite L, Hicks MH-R (2018) Patterns of civilian and child deaths due to war-related violence in Syria: a comparative analysis from the 
Violation Documentation Center dataset, 2011-16. Lancet Glob Health 6(1):e103-e110

4. Kotwal RS, Scott LL, Janak JC, Tarpey BW, Howard JT, Mazuchowski EL, Butler FK, Shackelford SA, Gurney JM, Stockinger ZT (2018) The effect of prehospital transport time, injury severity, and blood transfusion on survival of US military casualties in Iraq. J Trauma Acute Care Surg 85(1S):S112-S121

5. Champion HR, Holcomb JB, Young LA (2009) Injuries from explosions: physics, biophysics, pathology, and required research focus. J Trauma 66(5):1468-1477 (discussion 77)

6. Greer N, Sayer N, Kramer M, Koeller E, Velasquez T (2016) VA evidence-based synthesis program reports. Prevalence and epidemiology of combat blast injuries from the military cohort 2001-2014. Department of Veterans Affairs (US), Washington, DC

7. Smith S, Devine M, Taddeo J, McAlister VC (2017) Injury profile suffered by targets of antipersonnel improvised explosive devices: prospective cohort study. BMJ Open 7(7):e014697

8. Wolf SE, Kauvar DS, Wade CE, Cancio LC, Renz EP, Horvath EE et al (2006) Comparison between civilian burns and combat burns from Operation Iraqi Freedom and Operation Enduring Freedom. Ann Surg 243(6):786-792 (discussion 92-5)

9. Hicks MH-R, Dardagan H, Bagnall PM, Spagat M, Sloboda JA (2011) Casualties in civilians and coalition soldiers from suicide bombings in Iraq, 2003-10: a descriptive study. The Lancet 378(9794):906-914

10. Älgå A, Wong S, Shoaib M, Lundgren K, Giske CG, von Schreeb $\mathrm{J}$ et al (2018) Infection with high proportion of multidrug- resistant bacteria in conflict-related injuries is associated with poor outcomes and excess resource consumption: a cohort study of Syrian patients treated in Jordan. BMC Infect Dis 18(1):233

11. Nerlander MP, Leidman E, Hassan A, Sultan AS, Hussain SJ, Browne LB, Bilukha OO (2017) Fatalities from firearm-related injuries in selected governorates of Iraq, 2010-2013. Prehosp Disaster Med 32(5):548-555

12. Gerdin M, Roy N, Dharap S, Kumar V, Khajanchi M, Tomson G et al (2014) Early hospital mortality among adult trauma patients significantly declined between 1998-2011: three single-centre cohorts from Mumbai, India. PLoS ONE 9(3):e90064

13. Roy N, Kizhakke Veetil D, Khajanchi MU, Kumar V, Solomon $\mathrm{H}$, Kamble $\mathrm{J}$ et al (2017) Learning from 2523 trauma deaths in India-opportunities to prevent in-hospital deaths. BMC Health Serv Res 17(1): 142

14. Hunt P (2017) 7 Mass casualty incidents: a review of triage severity planning assumptions. Emerg Med J 34(12):A865

15. Hemat H, Shah S, Isaakidis P, Das M, Kyaw NT, Zaheer S et al (2017) Before the bombing: high burden of traumatic injuries in Kunduz Trauma Center, Kunduz, Afghanistan. PLoS ONE 12(3): 0165270

16. Trelles M, Stewart BT, Hemat H, Naseem M, Zaheer S, Zakir M et al (2016) Averted health burden over 4 years at Médecins Sans Frontières (MSF) Trauma Centre in Kunduz, Afghanistan, prior to its closure in 2015. Surgery 160(5):1414-1421

17. Dennis BM, Bellister SA, Guillamondegui OD (2017) Thoracic trauma. Surg Clin N Am 97(5):1047-1064 